Communication

\title{
Effects of Prenatal Tobacco and Wood-Fuel Smoke Exposure on Birth Weight in Sri Lanka
}

\author{
Malshani L. Pathirathna ${ }^{1,2, *}$ (D), Hansani M. Abeywickrama ${ }^{2}$, Kayoko Sekijima ${ }^{1}$, \\ Mieko Sadakata ${ }^{1}$, Naoshi Fujiwara ${ }^{3}$, Yoshiyuki Muramatsu ${ }^{1}$, Kuruppu M. S. Wimalasiri ${ }^{4}$, \\ Upali Jayawardene ${ }^{5}$, Darshana de Silva ${ }^{5}$ and Chandraratne M. B. Dematawewa ${ }^{4}$ \\ 1 Department of Nursing, Graduate School of Health Sciences, Niigata University, 2-746, Asahimachi-dori, \\ Chuo-ku, Niigata 951-8518, Japan; sekijima@clg.niigata-u.ac.jp (K.S.); atom@clg.niigata-u.ac.jp (M.S.); \\ murayosi@clg.niigata-u.ac.jp (Y.M.) \\ 2 Department of Nursing, Faculty of Allied Health Sciences, University of Peradeniya, Peradeniya 20400, \\ Sri Lanka; hansanimadushika87@gmail.com \\ 3 Department of Medical Technology, Graduate School of Health Sciences, Niigata University, 2-746, \\ Asahimachi-dori, Chuo-ku, Niigata 951-8518, Japan; fujiwaranaoshi@gmail.com \\ 4 Faculty of Agriculture, University of Peradeniya, Peradeniya 20400, Sri Lanka; \\ swarnaw@pdn.ac.lk (K.M.S.W.); mahindad@pdn.ac.lk (C.M.B.D.) \\ 5 Teaching Hospital Kurunegala, Colombo Road, Kurunegala 60000, Sri Lanka; upali818@yahoo.com (U.J.); \\ dharshandesilva@yahoo.com (D.d.S.) \\ * Correspondence: malshanilakshika@gmail.com or malshanilakshika@pdn.ac.lk; Tel.: +81-70-3604-4661 \\ Academic Editor: Sampath Parthasarathy \\ Received: 9 August 2017; Accepted: 23 September 2017; Published: 26 September 2017
}

\begin{abstract}
Low birth weight is a key public health problem in many developing countries, including Sri Lanka. Indoor air pollution from tobacco smoke and kitchen-fuel smoke are among the major contributors to low birth weight, factors of which there are little awareness of in Sri Lanka. We evaluated the effect of passive smoking and kitchen-fuel smoke exposure on birth weight. Seventy-six pregnant women were included in the study. Data were collected by questionnaire, and exposure assessment was conducted using a breath carbon monoxide monitor. Women exposed to second-hand tobacco smoke daily had a significantly lower mean gestational age at delivery (mean \pm standard error [SE]: $38.0 \pm 0.5$ weeks) than women who were exposed to second-hand tobacco smoke only once a week (mean \pm SE: $39.3 \pm 0.3$ weeks) $(p<0.05)$. Women who were exposed to tobacco smoke every day delivered neonates with significantly lower mean birth weight (mean \pm SE: $2703 \pm 135 \mathrm{~g}$ ) than women who were only exposed once a week (mean \pm SE: $3125 \pm 147 \mathrm{~g})(p<0.05)$. A one-minute increase in cooking time in a kitchen without a chimney increased women's expired air carbon monoxide concentration by $0.038 \mathrm{ppm}(p=0.006)$. Long-term exposure to wood-fuel smoke in a kitchen without a chimney can increase the risk of inhaling high concentrations of carbon monoxide.
\end{abstract}

Keywords: wood fuel smoke; passive smoking; birth weight; Sri Lanka

\section{Introduction}

Low birth weight (LBW) is defined as body weight less than $2500 \mathrm{~g}$ at birth. The World Health Organization estimates that more than 20 million LBW infants are born each year, and that LBW affects approximately $16 \%$ of all newborns in developing countries. The prevalence of LBW in Sri Lanka has been $16-17 \%$ for many years [1]. LBW is a major cause of infant morbidity and mortality, and developmental disabilities throughout life [2]. However, its rates vary across countries, even within the same region, and depend on socio-economic, behavioral, nutritional, and educational factors. Second-hand tobacco 
smoke exposure and indoor air pollution remain two major health problems, especially in developing countries, and the effect of passive smoking and cooking smoke on neonatal birth weight has been debated. Smoking during pregnancy can increase the risk of preterm birth, fetal growth restriction, low birth weight, sudden infant death syndrome, and behavioral problems [3-6]. Although multiple substances have been identified in cigarette smoke, carbon monoxide (CO) and nicotine are the two responsible for adverse effects on the developing fetus [7,8]. $\mathrm{CO}$ results from incomplete combustion of biomass such as tobacco or fuel [9]. Once inhaled, $\mathrm{CO}$ displaces oxygen to form a stable compound, carboxyhemoglobin $(\mathrm{COHb})$. This reduces the oxygen supply to peripheral tissues and organs, as well as to the fetus [10].

Many low- to middle-income countries still use biofuels (wood, agricultural waste, and animal dung) as the main source of energy for cooking and heating. A number of studies have demonstrated a clear association between solid-fuel use and lower respiratory tract infection and chronic obstructive lung diseases [11-13]. However, studies on adverse pregnancy outcomes are limited, and few studies have explored the effects of a combined exposure of tobacco smoke and wood-fuel smoke on the developing fetus.

Sri Lanka is a developing country which has recently been termed a lower- to middle-income country. Wood is the main source of cooking fuel in Sri Lanka, and is often burned over an open fire in an inefficient cooking stove. In addition, liquid petroleum gas and kerosene are used in some households. To our knowledge, this is the first study in Sri Lanka to evaluate the effects of second-hand tobacco smoke and wood-fuel smoke exposure on neonatal birth weight in relation to measured levels of expired CO.

\section{Materials and Methods}

This was part of a larger study carried out to identify maternal factors associated with neonatal birth weight. A prospective study was carried out in a tertiary care hospital in Sri Lanka between October 2015 and June 2016. A more detailed description of the subject recruitment procedure has been published separately [14]. In brief, 150 pregnant women who were between 18-24 weeks of gestation were initially included in the study. Exclusion criteria were risk factors according to obstetrical history (e.g., miscarriages/abortions, multiple fetuses, pregnancy-induced hypertension, and gestational diabetes mellitus) and wider medical history (e.g., psychiatric disorders or long-term cardiac, renal, lung, or gastrointestinal disease).

Eighty-seven pregnant women who visited the hospital antenatal clinic at 30 weeks of gestation were included in this part of the study. Data were collected using a pre-tested questionnaire that included questions on socioeconomic and demographic factors, exposure to tobacco smoke during the pregnancy, the frequency of exposure, relationship to the smoker, use of wood fuel for cooking, time spent cooking, and the characteristics of the kitchen. During the same clinic visit, maternal expired air $\mathrm{CO}$ concentrations and percentage of $\mathrm{COHb}$ were measured using a $\mathrm{piCO}^{+}$Smokerlyzer breath CO monitor (Bedfont Scientific Ltd., Maidstone, UK). The breath CO monitor is accurate within $\pm 2 \mathrm{ppm}$ and it was calibrated at least every six months in line with the manufacturer's recommendations. $\mathrm{CO}$ and $\mathrm{COHb}$ were each measured once only during the clinic visit. Women were asked to hold their breath for $15 \mathrm{~s}$ and then blow in to the instrument. Breath $\mathrm{CO}$ was measured in parts per million (ppm), and blood $\mathrm{COHb}$ was measured as percentage of oxygen replaced. CO levels were defined as equivalent to non-smoker (0-4 ppm), danger zone (5-6 ppm), smoker (7-10 ppm), and frequent smoker (11-16 ppm). The corresponding $\mathrm{COHb}$ levels were defined as $0-1.27,1.43-1.59$, 1.75-2.23, and 2.23-3.19\%, respectively [15]. The half-life of CO in human blood is approximately $5 \mathrm{~h}$, so measurements indicated recent exposure. Breath $\mathrm{CO}$ is not specifically a biomarker of smoking, but it also affected by environmental sources such as motor vehicle exhaust.

Maternal blood hemoglobin concentrations at the booking visit (weeks 6-8 of gestation) and weeks $28-30$ of gestation were obtained from individual pregnancy cards, whereas neonatal birth 
weight and gestational age at birth were obtained directly from the hospital records after deliveries. Trained research assistants administered the questionnaire and took measurements.

\subsection{Ethics}

The study was approved by the ethical review committees of the Graduate School of Health Sciences at Niigata University, Japan (No. 125), the Faculty of Allied Health Sciences, University of Peradeniya, and the teaching hospital at Kurunegala, Sri Lanka (ERC/2015/06). The study was conducted in compliance with the principles of the declaration of Helsinki. Written informed consent was obtained from the participants.

\subsection{Data Analyis}

Statistical analysis was carried out using Minitab version 17. Chi-squared test and two-sample $t$-test were used to compare groups exposed and not exposed to tobacco smoke and wood-fuel smoke. Correlations between continuous variables (maternal age, pre-pregnancy BMI, and gestational age at delivery) and neonatal birth weight were evaluated using Pearson's correlation coefficient. To test the effects of categorical variables (education level, monthly household income, residential area, parity, previous history of LBW, and history of miscarriage and/or abortion) on birth weight, the study used one way ANOVA followed by multiple regression analysis. The variables with $p<0.2$ in the ANOVA procedure were subsequently included in the multiple regression analysis as dummy variables in addition to the continuous variables mentioned above. Simple regression analysis was used to test the effects of wood-fuel exposure time on mean CO levels. $\mathrm{R}^{2}$ (adjusted for the number of predictors in the model) was used to show how much variance is explained by the models.

At the end of the data collection period, neonatal data were missing for 14 subjects because of ambiguity in hospital delivery registry records, as multiple similar maternal names made it difficult to accurately locate the study participants. The final analysis therefore consisted of maternal-neonatal data for 76 mother-child pairs.

\section{Results}

\subsection{Characteristics of Participants}

Table 1 shows participant characteristics, including smoking exposure and wood-fuel smoke exposure. None of the women were active smokers. Second-hand tobacco smoke exposure was found in $34.2 \%$ (26) of the women and 73 women $(96.0 \%)$ reported that they were exposed to wood-fuel smoke during the pregnancy. Of these 73 women, $12.3 \%$ were exposed in a kitchen not equipped with a chimney. Of the women exposed to second-hand tobacco smoke $(n=26), 69.2 \%$ had been exposed inside the house (closed space) and the others outside. Daily tobacco smoke exposure was reported by $61.5 \%$ and $38.5 \%$ reported that they were exposed approximately once a week. Of the women exposed to tobacco smoke, $69.2 \%$ had been exposed because their husbands smoked and $26.9 \%$ because of the father or father-in-law. 
Table 1. Characteristics of the participants.

\begin{tabular}{|c|c|c|c|c|c|c|}
\hline \multirow{3}{*}{ Variable } & \multirow{3}{*}{ All $(n=76)$} & \multirow{2}{*}{\multicolumn{2}{|c|}{ Exposed to Second Hand Tobacco Smoke }} & \multicolumn{3}{|c|}{ Wood Fuel Smoke Exposure } \\
\hline & & & & \multicolumn{2}{|c|}{ Exposed $(n=73)$} & \multirow[t]{2}{*}{ Not Exposed a $n=3$} \\
\hline & & Yes $(n=26,34.2 \%)$ & No $(n=50,65.8 \%)$ & $\begin{array}{c}\text { In a Kitchen with a } \\
\text { Chimney }(n=64,87.7 \%)\end{array}$ & $\begin{array}{l}\text { In a Kitchen without a } \\
\text { Chimney }(n=9,12.3 \%)\end{array}$ & \\
\hline Age (years) ${ }^{+}$ & $29.3 \pm 5.7$ & $27.8 \pm 6.4$ & $30.0 \pm 5.3$ & $29.7 \pm 5.7$ & $26.8 \pm 5.3$ & $27.3 \pm 6.5$ \\
\hline Pre-pregnancy BMI $\left(\mathrm{kg} / \mathrm{m}^{2}\right)^{\dagger}$ & $22.7 \pm 4.3$ & $22.3 \pm 4.5$ & $22.9 \pm 4.2$ & $22.8 \pm 4.3$ & $22.7 \pm 4.6$ & $20.0 \pm 2.3$ \\
\hline \multicolumn{7}{|l|}{ Education level, $n(\%)$} \\
\hline Up to primary & $9(12.0 \%)$ & $4(16.0 \%)$ & $5(10.0 \%)$ & $8(12.7 \%)$ & $1(11.1 \%)$ & - \\
\hline Secondary/higher & $66(88.0 \%)$ & $21(84.0 \%)$ & $45(90.0 \%)$ & $55(87.3 \%)$ & $8(88.9 \%)$ & $3(100.0 \%)$ \\
\hline \multicolumn{7}{|l|}{ Monthly household income, $n(\%)$} \\
\hline Up to 14,000 LKR & $15(20.0 \%)$ & $4(16.0 \%)$ & $11(22.0 \%)$ & $12(19.0 \%)$ & $3(33.3 \%)$ & - \\
\hline 14,000 to 32,000 LKR & $51(68.0 \%)$ & $18(72.0 \%)$ & $33(66.0 \%)$ & $43(68.2 \%)$ & $6(66.7 \%)$ & $2(66.7 \%)$ \\
\hline$\geq 32,000 \mathrm{LKR}$ & $9(12.0 \%)$ & $3(12.0 \%)$ & $6(12.0 \%)$ & $8(12.7 \%)$ & - & $1(33.3 \%)$ \\
\hline \multicolumn{7}{|l|}{ Residential area, $n(\%)$} \\
\hline Urban & $7(9.3 \%)$ & $3(12.0 \%)$ & $4(8.0 \%)$ & $7(11.1 \%)$ & - & - \\
\hline Sub-urban & $35(46.7 \%)$ & $11(44.0 \%)$ & $24(48.0 \%)$ & $30(47.6 \%)$ & $4(44.4 \%)$ & $1(33.3 \%)$ \\
\hline Rural & $33(44.0 \%)$ & $11(44.0 \%)$ & $22(44.0 \%)$ & $26(41.3 \%)$ & $5(55.6 \%)$ & $2(66.7 \%)$ \\
\hline \multicolumn{7}{|l|}{ Parity, $n(\%)$} \\
\hline Primiparous & $23(30.3 \%)$ & $7(26.9 \%)$ & $16(32.0 \%)$ & $15(23.4 \%)$ & $5(55.6 \%)$ & $3(100.0 \%)$ \\
\hline Multiparous & $53(69.7 \%)$ & $19(73.1 \%)$ & $34(68.0 \%)$ & $49(76.6 \%)$ & $4(44.4 \%)$ & - \\
\hline \multicolumn{7}{|l|}{ Previous history of LBW, $n(\%)$} \\
\hline Yes & $14(18.4 \%)$ & $6(23.1 \%)$ & $8(16.0 \%)$ & $12(18.8 \%)$ & $2(22.2 \%)$ & - \\
\hline No & $62(81.6 \%)$ & $20(76.9 \%)$ & $42(84.0 \%)$ & $52(81.2 \%)$ & $7(77.8 \%)$ & $3(100.0 \%)$ \\
\hline \multicolumn{7}{|l|}{ History of miscarriage and/or abortion, $n(\%)$} \\
\hline Yes & $20(26.3 \%)$ & $6(23.1 \%)$ & $14(28.0 \%)$ & $18(28.1 \%)$ & $2(22.2 \%)$ & - \\
\hline No & $56(73.7 \%)$ & $20(76.9 \%)$ & $36(72.0 \%)$ & $46(71.9 \%)$ & $7(77.8 \%)$ & $3(100.0 \%)$ \\
\hline Gestational age, weeks b, + & $39.1 \pm 1.4$ & $38.5 \pm 1.8$ & $39.2 \pm 1.1$ & $39.1 \pm 1.2$ & $38.2 \pm 2.4$ & $39.0 \pm 1.1$ \\
\hline \multicolumn{7}{|l|}{ Birth weight, $n(\%)$} \\
\hline$<2500 \mathrm{~g}$ & $13(17.1 \%)$ & $5(19.2 \%)$ & $8(16.0 \%)$ & $10(15.6 \%)$ & $2(22.2 \%)$ & $1(33.3 \%)$ \\
\hline$\geq 2500 \mathrm{~g}$ & $63(82.9 \%)$ & $21(80.8 \%)$ & $42(84.0 \%)$ & $54(84.4 \%)$ & $7(77.8 \%)$ & $2(66.7 \%)$ \\
\hline Hemoglobin levels at booking visit $(\mathrm{g} / \mathrm{dL})^{\dagger}(n=70)$ & $11.5 \pm 1.3$ & $11.4 \pm 1.3$ & $11.5 \pm 1.2$ & $11.5 \pm 1.2$ & $10.8 \pm 1.8$ & $11.6 \pm 0.4$ \\
\hline Anemic at booking visit ${ }^{c}, n(\%)$ & $19(27.1 \%)$ & $5(22.7 \%)$ & $14(29.2 \%)$ & $17(28.3 \%)$ & $2(28.6 \%)$ & - \\
\hline Non-anemic at booking visit ${ }^{d}, n(\%)$ & $51(72.9 \%)$ & $17(77.3 \%)$ & $34(70.8 \%)$ & $43(71.7 \%)$ & $5(71.4 \%)$ & $3(100.0 \%)$ \\
\hline 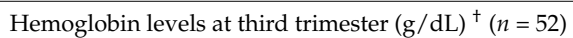 & $10.9 \pm 1.1$ & $10.9 \pm 1.1$ & $10.9 \pm 1.1$ & $11.0 \pm 1.0$ & $10.1 \pm 1.4$ & No data \\
\hline Anemic at third trimester ${ }^{c}, n(\%)$ & $25(48.1 \%)$ & $8(47.1 \%)$ & $17(48.6 \%)$ & $20(44.4 \%)$ & $5(71.4 \%)$ & No data \\
\hline Non-anemic at third trimester $\mathrm{d}, n(\%)$ & $27(51.9 \%)$ & $9(52.9 \%)$ & $18(51.4 \%)$ & $25(55.6 \%)$ & $2(28.6 \%)$ & No data \\
\hline
\end{tabular}

BMI: body mass index; LKR, Sri Lankan rupee; LBW, low birth weight. ${ }^{\dagger}$ Mean \pm SD. ${ }^{\text {a }}$ Women not exposed to wood fuel smoke reported use of liquid petroleum gas for cooking. ${ }^{\mathrm{b}}$ at the time of delivery. ${ }^{\mathrm{c}}$ Hemoglobin $<11 \mathrm{~g} / \mathrm{dL} .{ }^{\mathrm{d}}$ Hemoglobin $\geq 11 \mathrm{~g} / \mathrm{dL}$ 


\subsection{Relationship between Maternal Parameters and Birth Weight}

Estimates of Person's correlation coefficient showed that there was a moderate positive correlation between birth weight and gestational age at delivery $(\mathrm{r}=0.484 ; p=0.012)$. Pre-pregnancy BMI and maternal age had no significant correlation with birth weight $(p>0.05)$.

The fitted multiple regression model showed gestational age at delivery, monthly household income, parity, and previous history of LBW all had a significant impact on neonatal birth weight $(p<0.05)$. Women in the highest income category $(\geq 32,000$ LKR) delivered babies with significantly higher mean birth weight than women in the lowest monthly household income category $(p=0.013)$. Mean birth weight of the babies of primiparous mothers was $258 \mathrm{~g}$ below those of multiparous mothers $(p=0.045)$ (Table 2).

Table 2. Effects of maternal parameters on neonatal birth weight, multiple regression model for neonatal birth weight $(\mathrm{g})$.

\begin{tabular}{|c|c|c|c|c|}
\hline Term & Coefficient & $95 \% \mathrm{CI}$ & $t$-Value & $p$-Value \\
\hline Constant & -2239 & $-5558--1080$ & -1.35 & 0.183 \\
\hline \multicolumn{5}{|l|}{ Continuous variables } \\
\hline Pre-pregnancy BMI & 11.6 & $-14.0--37.2$ & 0.91 & 0.368 \\
\hline Gestational age at delivery & 107.3 & 28.3-186.4 & 2.71 & $0.009 * *$ \\
\hline \multicolumn{5}{|l|}{ Categorical variables } \\
\hline \multicolumn{5}{|l|}{ Area of residence (urban)-reference level } \\
\hline Area of residence (sub-urban) & -50 & $-436--335$ & -0.26 & 0.795 \\
\hline Area of residence (rural) & 241 & $-145--627$ & 1.25 & 0.217 \\
\hline \multicolumn{5}{|c|}{ Monthly household income (up to 14,000 LKR)-reference level } \\
\hline Monthly household income (14,000-32,000 LKR) & 204 & $-75--483$ & 1.46 & 0.148 \\
\hline Monthly household income (32,000 LKR) & 520 & $115-926$ & 2.56 & $0.013 * *$ \\
\hline \multicolumn{5}{|l|}{ Previous history of LBW (yes)-reference level } \\
\hline Previous history of LBW (no) & 311 & $24-597$ & 2.17 & $0.034 * *$ \\
\hline \multicolumn{5}{|l|}{ Parity (primiparous)-reference level } \\
\hline Parity (multiparous) & 258 & $6-510$ & 2.05 & $0.045^{* *}$ \\
\hline
\end{tabular}

\subsection{Exposure Response}

Even though it did not reach the level of statistical significance, women who were exposed to daily tobacco smoke had higher levels of expired $\mathrm{CO}$ and $\mathrm{COHb}$ compared with women who were exposed once a week. Similarly, women exposed to wood-fuel smoke in a kitchen without a chimney had higher levels of expired $\mathrm{CO}$ and $\mathrm{COHb}$ than women exposed in a kitchen with a chimney ( $p>0.05)$. Univariate analysis showed that women exposed to tobacco smoke on a daily basis had a significantly lower gestational age at delivery than women who were exposed once a week (mean \pm SE: $38.0 \pm 0.5$ weeks vs. $39.3 \pm 0.3$ weeks; $95 \%$ confidence interval [CI] for difference: $0.029-2.571 ; p<0.05$ ). They also delivered babies with significantly lower mean birth weight (mean \pm SE: $2703 \pm 135$ g vs. $3125 \pm 147$ g; 95\% CI for difference: 8-837; $p<0.05$ ). When the analysis was restricted to women with a kitchen chimney, the group exposed tobacco-smoke on daily basis still had significantly lower mean neonatal birth weight than the group exposed only once a week (Table 3). 
Table 3. Exposure to second hand tobacco smoke and wood fuel smoke and their relations to pregnancy outcomes.

\begin{tabular}{|c|c|c|c|c|c|c|c|c|c|c|c|c|c|c|}
\hline & & & & $n$ & $\begin{array}{l}\text { CO Conc. } \\
\text { (ppm) }\end{array}$ & $p$-Value & СОНb (\%) & $p$-Value & $\begin{array}{l}\text { Cooking } \\
\text { Time (min) }\end{array}$ & $p$-Value & $\begin{array}{l}\text { GA } \\
\text { (Weeks) }\end{array}$ & $p$-Value & $\begin{array}{l}\text { Birth } \\
\text { Weight (g) }\end{array}$ & $p$-Value \\
\hline \multirow{8}{*}{$\begin{array}{l}\text { Second-hand } \\
\text { tobacco } \\
\text { smoke } \\
\text { exposure }\end{array}$} & \multirow{7}{*}{ Yes } & All $^{\mathrm{a}}$ & & 26 & $1.885(0.178)$ & \multirow{8}{*}{$\begin{array}{l}0.104^{\mathrm{a}, \mathrm{h}} \\
0.205^{\mathrm{b}, \mathrm{e}} \\
0.099^{\mathrm{c}, \mathrm{d}} \\
0.102^{\mathrm{c}, \mathrm{f}} \\
0.633^{\mathrm{d}, \mathrm{f}}\end{array}$} & $0.969(0.049)$ & \multirow{8}{*}{$\begin{array}{l}0.445^{\mathrm{a}, \mathrm{h}} \\
0.099^{\mathrm{b}, \mathrm{e}} \\
0.109^{\mathrm{c}, \mathrm{d}} \\
0.109^{\mathrm{c}, \mathrm{f}} \\
0.798^{\mathrm{d}, \mathrm{f}}\end{array}$} & $108(14)$ & \multirow{8}{*}{$\begin{array}{l}0.054^{\mathrm{a}, \mathrm{h}} \\
0.666^{\mathrm{b}, \mathrm{e}} \\
0.721^{\mathrm{c}, \mathrm{d}} \\
0.721^{\mathrm{c}, \mathrm{f}} \\
0.488^{\mathrm{d}, \mathrm{f}}\end{array}$} & $38.5(0.4)$ & \multirow{8}{*}{$\begin{array}{l}0.078^{\mathrm{a}, \mathrm{h}} \\
0.045^{\mathrm{b}, \mathrm{e}, * *} \\
0.523^{\mathrm{c}, \mathrm{d}} \\
0.523^{\mathrm{c}, \mathrm{f}} \\
0.367^{\mathrm{d}, \mathrm{f}}\end{array}$} & $2865(107)$ & \multirow{8}{*}{$\begin{array}{l}0.408^{\mathrm{a}, \mathrm{h}} \\
0.046^{\mathrm{b}, \mathrm{e},{ }^{*}} \\
0.857^{\mathrm{c}, \mathrm{d}} \\
0.028^{\mathrm{c}, \mathrm{f}, \mathrm{w}^{\prime},} \\
0.381^{\mathrm{d}, \mathrm{f}}\end{array}$} \\
\hline & & \multirow{3}{*}{ Daily } & $\mathrm{All}^{\mathrm{b}}$ & 16 & $2.063(0.232)$ & & $1.025(0.073)$ & & $113(21)$ & & $38.0(0.5)$ & & $2703(135)$ & \\
\hline & & & $\begin{array}{l}\text { With kitchen } \\
\text { chimney }^{c}\end{array}$ & 13 & $2.231(0.257)$ & & $1.061(0.086)$ & & $111(25)$ & & $38.4(0.4)$ & & $2722(135)$ & \\
\hline & & & $\begin{array}{l}\text { Without kitchen } \\
\text { chimney }{ }^{d}\end{array}$ & 3 & $1.330(0.333)$ & & $0.867(0.067)$ & & $123(20)$ & & $36.6(2.3)$ & & $2617(497)$ & \\
\hline & & \multirow{3}{*}{$\begin{array}{l}\text { Once a } \\
\text { week }\end{array}$} & All $^{\mathrm{e}}$ & 10 & $1.600(0.267)$ & & $0.880(0.041)$ & & $101(18)$ & & $39.3(0.3)$ & & $3125(147)$ & \\
\hline & & & $\begin{array}{l}\text { With kitchen } \\
\text { chimney }{ }^{\mathrm{f}}\end{array}$ & 9 & $1.556(0.294)$ & & $0.889(0.045)$ & & $102(20)$ & & $39.3(0.3)$ & & 3194 (145) & \\
\hline & & & $\begin{array}{l}\text { Without kitchen } \\
\text { chimney } \mathrm{g}\end{array}$ & 1 & 2.000 & & 0.800 & & 90 & & 38.9 & & 2500 & \\
\hline & No & $\mathrm{All}^{\mathrm{h}}$ & & 50 & $2.340(0.207)$ & & $1.015(0.033)$ & & $144(12)$ & & $39.2(0.1)$ & & $2972(71)$ & \\
\hline \multirow{6}{*}{$\begin{array}{l}\text { Wood-fuel } \\
\text { smoke } \\
\text { exposure }\end{array}$} & \multirow{3}{*}{\multicolumn{2}{|c|}{$\begin{array}{l}\text { With kitchen } \\
\text { chimney }\end{array}$}} & All $^{\mathrm{i}}$ & 64 & $2.078(0.129)$ & \multirow{6}{*}{$\begin{array}{l}0.379^{\mathrm{i}, \mathrm{l}} \\
0.476^{\mathrm{j}, \mathrm{k}} \\
0.323^{\mathrm{j}, \mathrm{l}} \\
0.244^{\mathrm{j}, \mathrm{m}} \\
0.1111^{\mathrm{k}, \mathrm{m}} \\
0.262^{\mathrm{k}, \mathrm{n}} \\
0.158^{\mathrm{m}, \mathrm{n}}\end{array}$} & $0.989(0.026)$ & \multirow{6}{*}{$\begin{array}{l}0.614^{\mathrm{i}, \mathrm{l}} \\
0.991^{\mathrm{j}, \mathrm{k}} \\
0.638^{\mathrm{j}, \mathrm{l}} \\
0.086^{\mathrm{j}, \mathrm{m}} \\
0.071^{\mathrm{k}, \mathrm{m}} \\
0.359^{\mathrm{k}, \mathrm{n}} \\
0.190^{\mathrm{m}, \mathrm{n}}\end{array}$} & $130(10)$ & \multirow{6}{*}{$\begin{array}{l}0.717^{\mathrm{i}, \mathrm{l}} \\
0.104^{\mathrm{j}, \mathrm{k}} \\
0.236^{\mathrm{j}, \mathrm{l}} \\
0.741^{\mathrm{j}, \mathrm{m}} \\
0.235^{\mathrm{k}, \mathrm{m}} \\
0.688^{\mathrm{k}, \mathrm{n}} \\
0.281^{\mathrm{m}, \mathrm{n}}\end{array}$} & $39.1(0.2)$ & \multirow{6}{*}{$\begin{array}{l}0.301^{\mathrm{i}, \mathrm{l}} \\
0.103^{\mathrm{j}, \mathrm{k}} \\
0.498^{\mathrm{j}, \mathrm{l}} \\
0.434^{\mathrm{j}, \mathrm{m}} \\
0.610^{\mathrm{k}, \mathrm{m}} \\
0.102^{\mathrm{k}, \mathrm{n}} \\
0.409^{\mathrm{m}, \mathrm{n}}\end{array}$} & 2968 (65) & \multirow{6}{*}{$\begin{array}{l}0.268^{\mathrm{i}, \mathrm{l}} \\
0.559^{\mathrm{j}, \mathrm{k}} \\
0.426^{\mathrm{j}, \mathrm{l}} \\
0.441^{\mathrm{j}, \mathrm{m}} \\
0.342^{\mathrm{k}, \mathrm{m}} \\
0.554^{\mathrm{k}, \mathrm{n}} \\
0.538^{\mathrm{m}, \mathrm{n}}\end{array}$} \\
\hline & & & $\begin{array}{l}\text { Exposed to } \\
\text { second-hand } \\
\text { tobacco smoke } \mathrm{j}\end{array}$ & 22 & $1.955(0.203)$ & & $0.991(0.057)$ & & $107(17)$ & & $38.8(0.3)$ & & 2915 (109) & \\
\hline & & & $\begin{array}{l}\text { Not exposed to } \\
\text { second-hand } \\
\text { tobacco smoke }{ }^{k}\end{array}$ & 42 & $2.143(0.165)$ & & $0.988(0.264)$ & & $142(13)$ & & $38.2(0.2)$ & & $2995(81)$ & \\
\hline & \multirow{3}{*}{\multicolumn{2}{|c|}{$\begin{array}{l}\text { Without } \\
\text { kitchen } \\
\text { chimney }\end{array}$}} & All $^{1}$ & 9 & $2.899(0.873)$ & & $1.067(0.146)$ & & $138(19)$ & & $38.2(0.8)$ & & $2739(184)$ & \\
\hline & & & $\begin{array}{l}\text { Exposed to } \\
\text { second-hand } \\
\text { tobacco smoke } \mathrm{m}\end{array}$ & 4 & $1.500(0.289)$ & & $0.850(0.050)$ & & $115(17)$ & & $37.2(1.7)$ & & $2588(353)$ & \\
\hline & & & $\begin{array}{l}\text { Not exposed to } \\
\text { second-hand } \\
\text { tobacco smoke }^{n}\end{array}$ & 5 & $4.000(1.410)$ & & $1.240(0.242)$ & & $156(31)$ & & $38.9(0.3)$ & & 2860 (197) & \\
\hline
\end{tabular}

CO conc.: carbon monoxide concentration; COHb: carboxyhemoglobin; GA: gestational age; Superscript lowercase letters in $p$-value columns represent the groups used for pairwise comparison. Groups were compared using two-sample $t$-test. Descriptive statistics are expressed as mean (standard error of mean). ${ }^{* *} p<0.05$. 


\subsection{Time Spent Cooking and $\mathrm{CO}$ and $\mathrm{COHb}$ Measurements}

There was a weak positive correlation between cooking time and expired $\mathrm{CO}$ concentration $(\mathrm{r}=0.244 ; p=0.039)$ and $\mathrm{COHb}(\mathrm{r}=0.227 ; p=0.055)$ among women exposed to wood-fuel smoke. The correlation was strong when the analysis was restricted to women who were exposed in a kitchen without a chimney (CO: $\mathrm{r}=0.831, p=0.006$; percent $\mathrm{COHb}: \mathrm{r}=0.840, p=0.005)$. Regression analysis found that a 1-min increase in cooking time in a kitchen without a chimney increased expired $\mathrm{CO}$ by 0.038 ppm (95\% CI: $0.015-0.061 ; p=0.006)$ and COHb by $0.006 \%(95 \%$ CI: $0.002-0.010 ; p=0.005)$ (Figure 1).
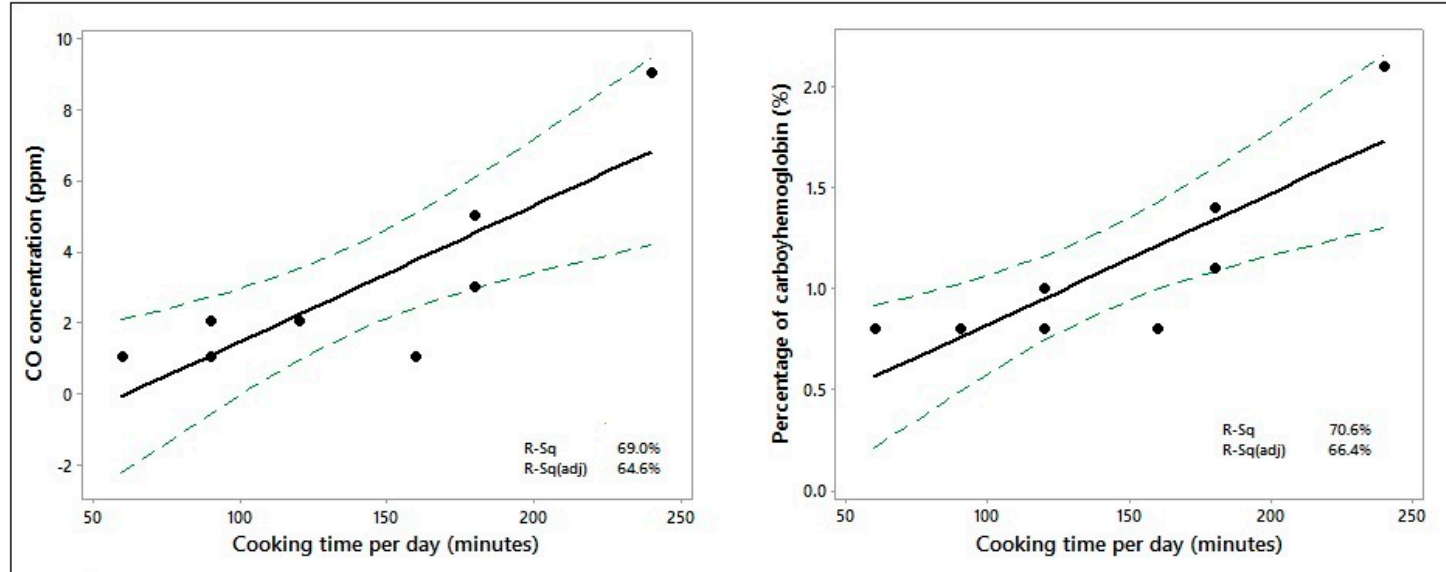

Figure 1. Time spent cooking in a kitchen without a chimney using wood fuel plotted against expired carbon monoxide $(\mathrm{CO})$ concentration and percentage of carboxyhemoglobin $(\mathrm{COHb})$.

\section{Discussion}

We found that women who were exposed to daily tobacco smoke and women exposed to wood-fuel smoke in a kitchen without a chimney had higher levels of breath $\mathrm{CO}$ and $\mathrm{COHb}$. The lack of significance might be because the biomarkers were measured several hours after the women left home. CO has a shorter half-life, so a gap of a few hours from exposure to measurement would reduce the level considerably. Exposure to motor vehicle exhaust fumes on the way to the clinic might also interfere with the estimate of the CO readings. A study in Peru found higher levels of $\mathrm{CO}$ in the air in the kitchens of bio-fuel users [16]. However, the shorter half-life of $\mathrm{CO}$ in the atmosphere than in the human body makes it difficult to make direct comparisons with our study.

Our findings are based on a small cohort, but this is one of the few prospective studies of which we are aware that assesses personal $\mathrm{CO}$ levels during pregnancy against exposure to second-hand tobacco and biomass fuel smoke. None of the women enrolled in our study were active smokers, as hardly any Sri Lankan women smoke. To date, no Sri Lankan studies have been published on second-hand smoke exposure during pregnancy. We found a significantly lower mean birth weight and lower gestational age in babies whose mothers were exposed to tobacco smoke during pregnancy on a daily basis compared with once a week. We also found a moderate positive correlation between gestational age and birth weight. The higher birth weight is probably a result of longer gestation, as the fetus is able to gain additional weight as a result. All the women who were exposed to second-hand tobacco smoke were also exposed to wood-fuel smoke. Second hand tobacco smoke could therefore have a confounding effect on the relationship between wood fuel smoke exposure and birth weight, and wood fuel smoke exposure could act as a confounding variable in the relationship between second hand tobacco smoke exposure and birth weight. It was difficult to test these confounding effects due to difficulty in carrying out a meaningful multiple regression analysis with this smaller sample 
size. Hackshaw [17] reported that adjusting for several factors can fail the sensible result or they can produce unreliable results when the sample size is small.

A number of studies $[16,18,19]$ have reported reduced mean birth weight and increased risk of LBW with bio-fuel smoke exposure. In Sri Lanka, almost all households use wood as the main source of kitchen fuel, and a small number also use liquid petroleum and kerosene. Expansion of liquid petroleum use is hindered by its high price. Almost all of the women in our study were exposed to wood-fuel smoke, so we were unable to make a fair comparison between those who were exposed and were not exposed to bio-fuel smoke. However, among $12.3 \%$ of the women in the study were exposed to wood-fuel smoke in a kitchen without a chimney. The mean birth weight of babies of these mothers was relatively low compared with those whose mothers were exposed to smoke in a kitchen with a chimney (mean \pm SE: $2739 \pm 184 \mathrm{~g}$ vs. $2968 \pm 65 \mathrm{~g}$ ), although the difference was not statistically significant. This lack of significance could however, perhaps be a result of the small sample size and the confounding effect of other variables. We expected to find the highest expired CO concentrations in women exposed to both wood-fuel smoke in a kitchen without a chimney and second-hand tobacco smoke, but the concentrations in this group were lower than in the group exposed to wood-fuel smoke in a kitchen with a chimney and no second-hand tobacco smoke $(p>0.05)$. Longer cooking times may account for the higher expired $\mathrm{CO}$ concentrations. In addition, the time since last exposure and the point of data collection is different for each woman may be one of the reasons behind unexpected $\mathrm{CO}$ values.

The lowest birth weight was reported in babies whose mothers cooked in a kitchen without a chimney and were exposed to second-hand tobacco smoke (mean \pm SE: $2588 \pm 353 \mathrm{~g}$ ), but the comparison was not statistically significant $(p>0.05)$.

Gomez et al. [20] reported that expired CO concentrations exceeding 5 ppm in mothers and their spouses were associated with decreased birth weight [19]. In our study, women who were exposed to smoke in a kitchen without a chimney had relatively higher expired CO concentrations, which were close to the upper margin of the non-smoker level. The time spent cooking (using wood fuel) in a kitchen without a chimney was strongly correlated with the levels of expired $\mathrm{CO}$ and $\mathrm{COHb}$. We also found that almost all the women without a kitchen chimney had a monthly household income below $32,000 \mathrm{LKR}$ and did not live urban areas.

A number of possible tactics for reducing bio-fuel smoke exposure have been suggested [13]. These include improved cooking devices, alternative fuel sources, improved living environment, and modifying user behaviors to reduce exposure. Pre-processing (drying) the fuel, good maintenance of stoves, and building stoves at waist level are achievable strategies in Sri Lanka, where the majority of people have a low to medium household income. Using a pot lid while cooking to conserve heat, pre-soaking foods like grains and dhal to reduce cooking time, and not using exhaled breath to start a fire in a wood stove are also simple modifications to user behavior to reduce their exposure to kitchen fuel smoke. However, structural modifications to house (fireplace, chimney, windows, ventilation holes, and separate kitchen) would not be financially feasible in poor community settings. An interventional study, in which efficient stoves were provided to pregnant women in the second and third trimester, found an increase of $89 \mathrm{~g}$ in birth weight of babies whose mothers switched from using open fires to stoves [21]. Policymakers could therefore provide cost-effective, efficient stoves to reduce smoke exposure in low-resource communities in Sri Lanka. We found that a considerable proportion of pregnant women were exposed to second-hand tobacco smoke and to wood-fuel smoke. Many households in Sri Lanka still rely on wood for their daily cooking needs, and the women of reproductive age carry a substantial burden of cooking duties, resulting in daily exposure to high concentrations of $\mathrm{CO}$ and other air pollutants.

Provision of antenatal education is recommended, to encourage families to shift toward voluntary smoking restrictions at home and a purposeful reduction of exposure to smoke by pregnant women. Primary health care providers should perform risk assessment, increase awareness, and provide guidance on exposure reduction. 


\section{Limitations}

The small cohort is the major limitation of this study. We measured the CO levels during clinic visits by the participants. The time between exposure and measurement may therefore vary from person to person, as could the level of exposure to other sources of $\mathrm{CO}$ (such as vehicle exhaust gases) on the way to the clinic, which could affect the accuracy of the $\mathrm{CO}$ readings. We did not assess the time gap between the most recent exposure and the point of data collection, and this may cause biased results because of the short half-life of CO. In addition, we were limited to the primary fuel type, although some women may use firewood in combination with liquid petroleum gas and/or kerosene.

Despite the limitations, this is the first study of which we are aware in which the effects of second-hand tobacco smoke and wood-fuel use on neonatal birth weight have been assessed among Sri Lankan women. It is also the first prospective study to our knowledge that provides quantitative exposure response data on neonatal birth weight in relation to measured levels of CO in a Sri Lankan context. Data from this small study can be used to design further large scale studies in Sri Lankan context to assess the effects of smoke exposure on human health. We recommend future studies to assess exposure to smoke among pregnant women and its effects on neonatal birth weight, addressing some of the limitations of this study.

\section{Conclusions}

Second-hand tobacco smoke exposure in Sri Lankan pregnant women is followed by low mean birth weights of their babies. Long-term exposure to wood-fuel smoke in a kitchen without a chimney can increase the risk of inhaling high concentrations of $\mathrm{CO}$.

Acknowledgments: The authors thank the women who participated in this study, obstetricians, special-grade nursing officers, and the staff nurses of the antenatal clinics for their support of this study. This study received no specific grant from any public, commercial, or not-for-profit sector. The authors also thank Dean Meyer and Melissa Leffler, from Edanz Group (www.edanzediting.com/ac) for editing drafts of this manuscript.

Author Contributions: M.L.P., H.M.A., K.S., M.S., N.F., U.J. and D.d.S. contributed to the conception and design of this study. M.L.P., C.M.B.D. and K.S. analyzed the data and M.L.P. wrote the manuscript. K.S., M.S., N.F., Y.M., K.M.S.W. and C.M.B.D. critically reviewed the manuscript and supervised the whole study process. All authors read and approved the final manuscript.

Conflicts of Interest: The authors declare no conflict of interest.

\section{References}

1. Ministry of Health. Annual Health Bulletin; Ministry of Health, Nutrition and Indigenous Medicine, Medical Statistics Unit: Colombo, Sri Lanka, 2014.

2. World Health Organization and United Nations Children's Fund. Low Birth Weight; Country, Regional and Global Estimates. Available online: https:/ / www.unicef.org/publications/files/low_birthweight_from_EY. pdf (accessed on 10 April 2017).

3. Wisborg, K.; Henriksen, T.B.; Hedegaard, M.; Secher, N.J. Smoking during pregnancy and preterm birth. Br. J. Obstet. Gynaecol. 1996, 103, 800-805. [CrossRef] [PubMed]

4. Zheng, W.; Suzuki, K.; Tanaka, T.; Kohama, M.; Yamagata, Z. Okinawa Child Health Study Group. Association between maternal smoking during pregnancy and low birth weight: Effects by maternal age. PLoS ONE 2016, 11, e0146241. [CrossRef]

5. Shah, T.; Sullivan, K.; Carter, J. Sudden infant death syndrome and reported maternal smoking during pregnancy. Am. J. Public Health 2006, 96, 1757-1759. [CrossRef] [PubMed]

6. Tran, P.L.; Lehti, V.; Lampi, K.M.; Helenius, H.; Suominen, A.; Gissler, M.; Brown, A.S.; Sourander, A. Smoking during pregnancy and risk of autism spectrum disorder in a Finnish national birth cohort. Paediatr. Perinat. Epidemiol. 2013, 27, 266-274. [CrossRef] [PubMed]

7. Longo, L.D. The biological effects of carbon monoxide on the pregnant woman, fetus, and newborn infant. Am. J. Obstet. Gynecol. 1977, 129, 69-103. [CrossRef]

8. Seidman, D.; Mashiach, S. Involuntary smoking and pregnancy. Eur. J. Obstet. Gynecol. Reprod. Biol. 1991, 41, 105-116. [CrossRef] 
9. Smith, K.R. Biofuels, Air Pollution, and Health: A Global Review, 1st ed.; Plenum Press: New York, NY, USA, 1987; pp. 369-373 ISBN 978-1-4613-0891-1.

10. Boy, E.; Bruce, N.; Delgado, H. Birth weight and exposure to kitchen wood smoke during pregnancy in rural Guatemala. Environ. Health Perspect. 2002, 110, 109-114. [CrossRef] [PubMed]

11. Smith, K.R.; Samet, J.M.; Romieu, I.; Bruce, N. Indoor air pollution in developing countries and acute lower respiratory infections in children. Thorax 2000, 55, 518-532. [CrossRef] [PubMed]

12. Ezzati, M.; Kammen, D.M. Quantifying the effects of exposure to indoor air pollution from biomass combustion on acute respiratory infections in developing countries. Environ. Health Perspect. 2001, 109, 481-488. [CrossRef] [PubMed]

13. Bruce, N.; Perez-Padilla, R.; Albalak, R. Indoor air pollution in developing countries: A major environmental and public health challenge. Bull. World Health Organ. 2000, 78, 1078-1092. [PubMed]

14. Pathirathna, M.L.; Sekijima, K.; Sadakata, M.; Fujiwara, N.; Muramatsu, Y.; Wimalasiri, K.M. Impact of Second Trimester Maternal Dietary Intake on Gestational Weight Gain and Neonatal Birth Weight. Nutrients 2017, 9, 627. [CrossRef] [PubMed]

15. piCO $^{+\mathrm{TM}}$ Smokerlyzer ${ }^{\circledR}$ Operating Manual. Available online: https://www.bedfont.com/file.php?f= ZmlsZSMjNzE0 (accessed on 18 December 2016).

16. Yucra, S.; Tapia, V.; Steenland, K.; Naeher, L.P.; Gonzales, G.F. Maternal exposure to biomass smoke and carbon monoxide in relation to adverse pregnancy outcome in two high altitude cities of Peru. Environ. Res. 2014, 130, 29-33. [CrossRef] [PubMed]

17. Hackshaw, A. Small studies: Strengths and limitations. Eur. Respir. J. 2008, 32, 1141-1143. [CrossRef] [PubMed]

18. Pope, D.P.; Mishra, V.; Thompson, L.; Siddiqui, A.R.; Rehfuess, E.A.; Weber, M.; Bruce, N.G. Risk of low birth weight and stillbirth associated with indoor air pollution from solid fuel use in developing countries. Epidemiol. Rev. 2010, 32, 70-81. [CrossRef] [PubMed]

19. Siddiqui, A.R.; Gold, E.B.; Yang, X.; Lee, K.; Brown, K.H.; Bhutta, Z.A. Prenatal exposure to wood fuel smoke and low birth weight. Environ. Health Perspect. 2008, 116, 543-549. [CrossRef] [PubMed]

20. Gomez, C.; Berlin, I.; Marquis, P.; Delcroix, M. Expired air carbon monoxide concentration in mothers and their spouses above 5 ppm is associated with decreased fetal growth. Prev. Med. 2005, 40, 10-15. [CrossRef] [PubMed]

21. Thompson, L.M.; Bruce, N.; Eskenazi, B.; Diaz, A.; Pope, D.; Smith, K.R. Impact of reduced maternal exposures to wood smoke from an introduced chimney stove on newborn birth weight in rural Guatemala. Environ. Health Perspect. 2011, 119, 1489-1494. [CrossRef] [PubMed] 